\title{
Application of Team-Based Learning at a Health Science Course: A Case Study
}

\author{
By Elif Bengü
}

The purpose of this study is to identify students' reactions to the implementation of team-based learning as an instructional strategy in a pharmacology course in the context of a Turkish university. Team-based learning is defined as an active form of learning that not only encourages individual effort but also team involvement to learn in an academic setting. Team-based learning is one of the learning techniques/methods that is increasingly being used in medical education. Literature shows that in teambased learning students apply the concepts at the time they are learned in the classroom, before the exams, as opposed to traditional lecturing, in which the concepts that are learned are later tested in the exams. Furthermore, research supports that faculty are more engaged with their students in team-based learning, since it affords instructors the ability to readily identify what their students are achieving, as opposed to traditional lecturing or other group approaches. There are limited studies in Turkey that examine the applications of team-based learning in a higher education setting. Therefore, this study describes the use of the team-based learning technique in an undergraduate health science course in Turkey. The initial results indicate that this instructional strategy was beneficial for students' learning.

Keywords: active learning, adult education, health science, higher education, high power distance, large classroom, team-based learning.

\section{Introduction}

Although educators in teacher training programs often encourage their students to use alternative teaching methods, when it comes to teaching these methods, traditional methods are mostly used in the classroom. The situation is even more troublesome in other departments in the universities, especially when it comes to departments where critical thinking skills and effective teamwork are part of the skillset that students are required to obtain (Hrynchak \& Batty, 2012).

In their 2017 study, Frisby, Slone, and Bengu highlighted that the application of instructional methods can show cultural differences and as a result of that students and instructors may view the teaching and learning process differently. Turkey scores high on power distance, which is one of the independent dimensions of the culture that was identified by Hofstede (as cited in Frisby, Slone, \& Bengu, 2017). In cultures with a high power distance, power is centralized and there is a strict hierarchical order (Frisby et al., 2017). Research shows that the Turkish higher education system has the elements of traditional

*Assistant Professor, School of Educational Science, Abdullah Gül University, Kayseri, Turkey, 38080 . 
authoritative culture (Tatar, 2005; Yıldırım, 2006; Topbaş, 2013). Turkish higher education is highly teacher-centered, where teachers do not expect to be questioned or criticized and students are not expected to speak up in the classroom (Tatar, 2005; Y1ldırım, 2006; Topbas, 2013)

According to the results of Bidabadi, Isfahani, Rouhollahi, and Khalili (2016) and Michaelsen, Parmelee, McMahon and Levine (2008), one of the best teaching approaches for higher education is the mixed method, which involves combining the student-centered method with the teacher-centered one.

During the search for an approach that combines the student-centered method with the teacher-centered one, the researcher found team-based learning (TBL) as an attractive option. In TBL, students take initiative in their learning process, as opposed to the traditional teaching method, where students are passive learners. In this method, teachers still play an important role, in which they act as facilitators and advisers (Zeng, Xiang, Zeng, \& Zuo, 2017).

TBL is defined as a learner-centered, teacher-directed instructional approach that fosters active learning and promotes a high level of cognitive skills (Thompson et al., 2007; Nieder, Parmelee, Stolfi, \& Hudes, 2005; Michaelsen, Parmelee, McMahon, \& Levine, 2008; Parmelee, Michaelsen, Cook, \& Hudes, 2012; Dolmans, Michaelsen, Van Merrienboer, \& Van der Vleuten, 2015). On the one hand, healthcare professionals are expected to have strong critical thinking and teamwork skills (Hrynchak \& Batty, 2012). On the other, TBL provides a learning environment where students have to work in teams and solve problems. It is not surprising, therefore, that Thompson et al. (2007) and others (McInerney \& Fink 2003; Searle et al., 2003; Nieder, Parmelee, Stolfi, \& Hudes 2005; Chung, Rhee, Baik, \& Oh-Sun, 2009; Shellenberger et al. 2009; Wiener, Plass, \& Marz, 2009; Fatmi, Hartling, Hillier, Campbell, \& Oswald, 2013; Emke, Butler, \& Larsen, 2016) have mentioned in their papers that TBL is an instructional strategy that is being employed increasingly in medical education. Because of these qualities, TBL can also be an appropriate method for other fields in higher education.

Before continuing with the study, it is worth highlighting the differences between TBL and problem-based learning (PBL), since both methods are commonly used in higher education and are often confused (Salam et al., 2016). PBL was developed in medical school in the late 1960s (Dolmans, Michaelsen, Van Merrienboer, \& Van der Vleuten, 2015) as "a student centered as opposed to a teacher centered approach" (Dolmans, et al., 2015, p. 354). Similarly, TBL was designed by Michaelsen in 1970 to encourage teamwork rather than group work. His aim was to lift the classroom spirit and decrease the teaching pressure because of the growing numbers of students in his own classroom (Michaelsen et al., 2008).

The two common characteristics of PBL and TBL are (i) learning about professionally relevant problems and (ii) learning in small groups or teams (Dolmans et al., 2015).

The main differences between these two teaching methods are demonstrated in Table 1. 
Table 1. Main Differences between PBL and TBL

\begin{tabular}{|c|c|c|}
\hline $\begin{array}{c}\text { Instruction } \\
\text { characteristic }\end{array}$ & $\begin{array}{c}\text { Problem-based Learning } \\
\text { (PBL) }\end{array}$ & Team-based Learning (TBL) \\
\hline $\begin{array}{l}\text { Number of } \\
\text { teachers and } \\
\text { presence }\end{array}$ & $\begin{array}{l}\text { Many teachers; one per } \\
\text { small group. Teacher } \\
\text { physically present in each } \\
\text { group }\end{array}$ & $\begin{array}{l}\text { One teacher for many small } \\
\text { teams. Teacher not physically } \\
\text { present in each team. }\end{array}$ \\
\hline Rooms & $\begin{array}{l}\text { Groups work in different } \\
\text { small rooms. }\end{array}$ & $\begin{array}{l}\text { Teams work in the same large } \\
\text { room in teams. }\end{array}$ \\
\hline $\begin{array}{l}\text { Pre-class } \\
\text { reading/exposure } \\
\text { to new content }\end{array}$ & $\begin{array}{l}\text { No mandatory pre-class } \\
\text { reading assignment before } \\
\text { group discussion. Exposure } \\
\text { to new content after initial } \\
\text { group discussion, during } \\
\text { self-study and during final } \\
\text { group discussion }\end{array}$ & $\begin{array}{l}\text { Mandatory pre-class reading } \\
\text { assignment before team } \\
\text { discussion. Exposure to new } \\
\text { content before the team } \\
\text { discussion. }\end{array}$ \\
\hline Prior knowledge & $\begin{array}{l}\text { Students are not tested, but } \\
\text { encouraged to activate their } \\
\text { prior knowledge by means } \\
\text { of an initial group } \\
\text { discussion. }\end{array}$ & $\begin{array}{l}\text { Students are tested } \\
\text { individually and as a team to } \\
\text { check their understanding of } \\
\text { the reading assignments and } \\
\text { prior knowledge. }\end{array}$ \\
\hline $\begin{array}{l}\text { Teacher- versus } \\
\text { student-initiated } \\
\text { decisions about } \\
\text { content to be } \\
\text { studied }\end{array}$ & $\begin{array}{l}\text { Students generate issues for } \\
\text { self-study; students define } \\
\text { what is not yet well } \\
\text { understood after an initial } \\
\text { group discussion of } \\
\text { professionally relevant } \\
\text { problem. }\end{array}$ & $\begin{array}{l}\text { Teacher defines content for } \\
\text { pre-class study based on } \\
\text { knowledge required for } \\
\text { application problems that will } \\
\text { be given during the unit. } \\
\text { Teacher decides, based on the } \\
\text { results of a group test, which } \\
\text { issues are not yet well } \\
\text { understood. }\end{array}$ \\
\hline Feedback & $\begin{array}{l}\text { Feedback } \\
\text { confirmatory } \\
\text { corrective) from peers } \\
\text { during the final group } \\
\text { discussion and if necessary } \\
\text { from the teacher. No } \\
\text { testing and no inter-group } \\
\text { discussions. } \\
\end{array}$ & $\begin{array}{l}\text { Feedback (both confirmatory } \\
\text { and corrective) from peers and } \\
\text { the teacher during team test, } \\
\text { but also from inter-team } \\
\text { discussions after teams have } \\
\text { revealed their choices, } \\
\text { challenged others and } \\
\text { attempted to defend their own. }\end{array}$ \\
\hline Peer feedback & $\begin{array}{l}\text { No structured peer } \\
\text { evaluations/feedback. }\end{array}$ & $\begin{array}{ll}\text { Structured } & \text { peer } \\
\text { evaluations/feedback. }\end{array}$ \\
\hline Problems & $\begin{array}{l}\text { Reasoning around } \\
\text { problems with no specified } \\
\text { questions. }\end{array}$ & $\begin{array}{l}\text { Reasoning around problems } \\
\text { with associated questions. }\end{array}$ \\
\hline
\end{tabular}

Source: Dolmans et al., 2015. 


\section{What is Team-based Learning?}

There are various definitions of team-based learning (TBL). In simple form, it is a teaching paradigm that promotes active learning where single instructors manage multiple small teams. TBL consists of learning activities and phases. These steps are described in detail in Michaelsen, Parmelee, McMahon, \& Levine's (2008) study.

In conjunction with Zeng, Xiang, Zeng, \& Zuo (2017), in this study we separate TBL in three phases. Phase I includes grouping and assigning readings; Phase II consists of an Individual Readiness Assurance Test (iRAT), a Team Readiness Assurance Test (tRAT) and discussion; and lastly, phase III involves the teamwork, second phase of discussion and peer evaluation.

\section{Phase I: Pre-TBL Session}

1. Grouping. The instructor must create a team as diverse as possible, where there will be an "opportunity to develop into learning teams" (Michaelsen et al. 2008). The teams must be heterogeneously formed and coached by the instructor. The instructor has to have at least a slight idea about her students' usual performances, so that she can have teams with diverse groups of students. 2. Assigned readings. This period lasts approximately one week. A week prior to the assigned topic, students are given readings and other assignments that are related to the topic and are expected to learn from the material that was provided. The reference material should not exceed five pages and should be within the students' level of understanding (Michaelsen et al. 2008). In this stage, accountability is really important. If students attend the session without reading the assigned material, the teams will not be able to function as it was expected. Before the instructor provides the assigned readings to the students, she has to emphasize why students are accountable for coming to class prepared. In TBL, accountability has shown itself as one of the essential elements (Sutherland et al. 2013).

\section{Phase II: TBL Session}

1. iRAT. Students are expected to attend the next class period prepared to take an individual readiness assurance test (iRAT) on the assigned materials. Each student is examined individually at the beginning of the session and the papers are collected in 15 minutes. The iRAT questionnaire should include between eight to ten questions, which should be in multiple-choice format.

2. tRAT. After students turn in their answers to the individual test, they are asked to re-take the same test within their groups. This time, the teams must discuss it amongst themselves. In this step, it is ideal to see the students reach an agreement if they have not selected the same answers for the iRAT questions. This type of exam is called a team readiness assurance test (tRAT). After they come to a decision as a group, the students are expected to check the correctness of their decision using a scratch-able answer sheet (Michaelsen et 
al., 2008). Each team receives one scratch-able answer sheet and scratches off the covering of one of four or five boxes in search of a mark or star, which indicates that they have found the correct answer. In this study, four boxes were used.

3. Written appeals. Students have the opportunity to appeal any questions that are on the test or were missed on the test. This study did not include written appeals.

4. Feedback. After the tRAT, the instructor is expected to provide oral feedback to the teams. When the instructor goes over the questions one by one, she asks each team to indicate their response. If the instructor sees any answer that is not correct, she has to provide immediate feedback. The feedback has to come before the application session, in order to clarify any misunderstandings about the topic that was presented through the readings or in the previous sessions. In this study, there were ten teams. Since it can be challenging to get the answers simultaneously from the groups, we used option cards (Michaelsen, 2008). Option cards, each marked A, B, C, D and E, were designed as a sign so that everyone could see it.

\section{Phase III: TBL Application Session}

1. Teamwork in the classroom. The instructor provides an assignment/case study to each group and asks them to solve some sort of a problem to promote discussion both within and between groups (Michaelsen et al., 2008). The assignment should be the same one for each group. Michaelsen et al. (2008) talk in detail about the kind of assignments and questions the instructors should be asking students "to process information at higher levels of cognitive complexity."

2. Reporting. After teams write their reports for the assignment/case study, each team presents its results either sequentially or simultaneously. If time permits, the instructor can provide immediate feedback to the reports in the classroom. Otherwise, she can send the feedback to the group through e-mail.

3. Peer Evaluation. At the end of the session, teams are asked to evaluate their teammates' performance in the activities. This study did not include peer evaluation.

\section{Using Team-based Learning in the Classroom}

Literature review shows that numerous instructors apply team-based learning (TBL) in their health science courses (Terenzini, Cabrera, Colbeck, Parente, \& Bjorklund, 2001; Haidet et al., 2012; Prince, 2004; Nieder, Parmelee, Stolfi, \& Hudes, 2005; Michaelsen, Sweet, \& Parmalee, 2009; Koles, Stolfi, Borges, Nelson, \& Parmelee, 2010; Emke, Butler, \& Larsen, 2016). These researchers are providing positive outcomes and reports in their studies.

As an educator, this author felt the need to put this method to the test in the context of a higher education institution in Turkey. First, it was necessary to 
find an instructor who would be interested in using an alternative teaching method in his or her classroom. This was not an easy task. The instructors who were approached were hesitant. Finally, an instructor was found who was willing to give it a try in one of her evening classes. After the first meeting with the researcher, she was provided with an orientation session about TBL. During this session, the dates on which she would apply the method were also determined. She was asked to provide an introduction to her students, the reasons that she chose to use TBL, and suggestions on how she planned on conducting the session. She was also requested to arrange the grouping and reading assignments for Phase I; quiz for Phase II; and activities for Phase III. She was assisted throughout the process. One main problem was to find scratch-able answer sheets, as well as big cards for the sign cards. Since these materials were not available for purchase in Turkey, the researcher made them.

Subsequently, the folders were arranged per team. Each folder included: an iRAT with 10 questions, a scratch-able answer sheet for the tRAT, sign cards (A, B, C, D, E), a case study, blank sheets on which to write their reports, and the evaluation form (only for the first session). In this study, the class was divided into 10 teams, with six to seven students per team. Seating was rearranged and grouped according to the number of teams. Students were called on one by one and were asked to sit with their assigned team. All the steps of TBL were followed, except for the written appeals and peer evaluations, partly because of the lack of preparedness of the students and partly due to time concerns.

The steps and phases that were taken in this study can be seen in Figure 1.

Figure 1. Team-Based Learning Instructional Activity

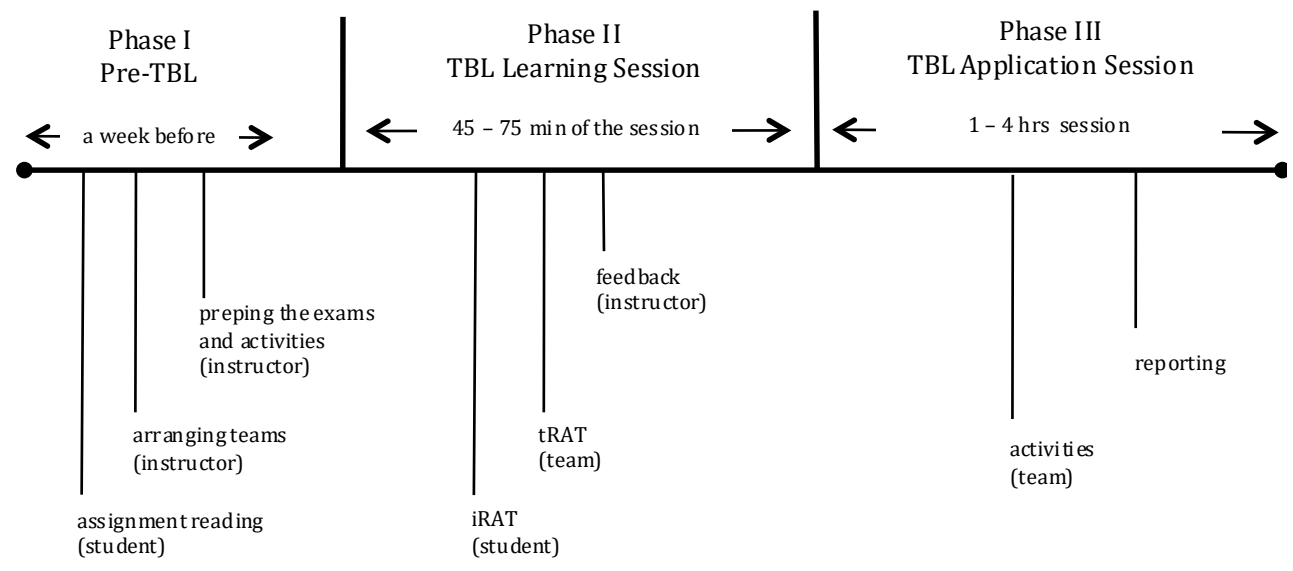

Source: Michaelsen, Sweet, \& Parmalee, 2009

\section{Methodology}

This case study took place at a private university in Turkey during the fall semester of 2016. Fraenkel, Wallen, and Hyun (2011) defined case study as one of the common forms of qualitative research. According to their definition, 
"a case study is a detailed analysis of one or a few individuals."

The instructor who took part in the study is the program director of the First and Emergency Aid program in the Vocational School of Health Services. The aim of this program is to educate technicians to be able to give treatment at first sight during an illness or accident and transport the patient or the injured person to the hospital in a specially equipped ambulance. It is a two-year program that offers both day and evening classes. Evening classes are designed for students who work during the day.

In this study, a Pharmacology course consisting of 62 enrolled students was used as the data source. It is a required course that meets once a week and goes from 6:00 pm until 9:00 pm. About 90\% of the student population has day jobs and by the time they come to the class they are usually worn out. The classroom is located in a very old building with low ceilings. In addition, here is hardly any ventilation in the classroom. Due to these factors, the students' motivation level to participate in the session is low. In fact, the instructor herself claims that she doesn't feel motivated to conduct the class, since she has already been teaching all day.

\section{Data Collection and Analysis}

Data sources included two observations from the same group of students, which took place three weeks apart. In the first observation, a survey was used consisting of 14 questions: a Likert-scale questionnaire and two open-ended questions. A three-item Likert-scale was used in the survey; agree, somewhat agree and do not agree. This type of survey was given to students to check their basic reaction to the TBL methodology, as well as to gain insight into their perception of it.

The survey with the open-ended questionnaire was given to students after the first session, while the focus group study with two groups was conducted after the second session to triangulate the data. Each focus group contained six to eight people who were picked randomly. The two to three questions asked at the focus group sessions lasted approximately 60 minutes. They were audiotaped and transcribed by the researcher. The data was then analyzed with SPSS quantitative software.

\section{Results}

Students reported on their reactions and what they would like to see done differently through the open-ended questions that were provided at the end of the Likert-scale survey. Similar questions were also asked during the focus group study. The results were summarized into five categories: team-based learning (TBL) as a method; teamwork; scratch-able cards; reporting/evaluation and classroom decorum. The statistical results of the questions that we thought are crucial (Questions 1, 9, 10, 11 and 12) are shown in Tables 2, 3, 4, 5 and 6. In the tables, "Katılmıyorum" means "Do Not Agree;" "Kismen Kat1liyorum" 
means "Somewhat Agree;" and "Kat1lyorum" means, "Agree."

\section{Team-based Learning (TBL) as a Method}

In Question 1 (Table 2), the students were asked to indicate if they felt they learned in this session compared to the other session of the course, and $58.06 \%$ of the students said "I agree." On question 10 (Table 3), 67.74\% of the students said that what they have learned in this session makes sense and on Question 12 (Table 4), 61.29\% of the students expressed that they understood the main concepts.

To gain more insight into their perception of using TBL as a method in the classroom, we asked the focus group similar questions. Students in the focus group expressed that they were more active compared to the other sessions of this course. Students in this group saw TBL as a technique where students are engaged and become active learners. They defined the method as interactive, interesting and student-centered.

Students in the focus group further defined TBL as "a material that is upto-date." They expressed that this alternative teaching method makes the session more interactive and interesting and as a result of that they said, "they learn." They also mentioned that TBL encouraged them to ask questions and discuss, which does not happen often in their courses. One student characteristically commented:

"(Through team-based learning) instruction can still take place and be fun at the same time ... through this session we have seen that an instructor has the capability to make the session more fun ... and we learn better."

Table 2. Question 1 I Have Learned a Lot in This Session Compared To the Other Sessions of This Course

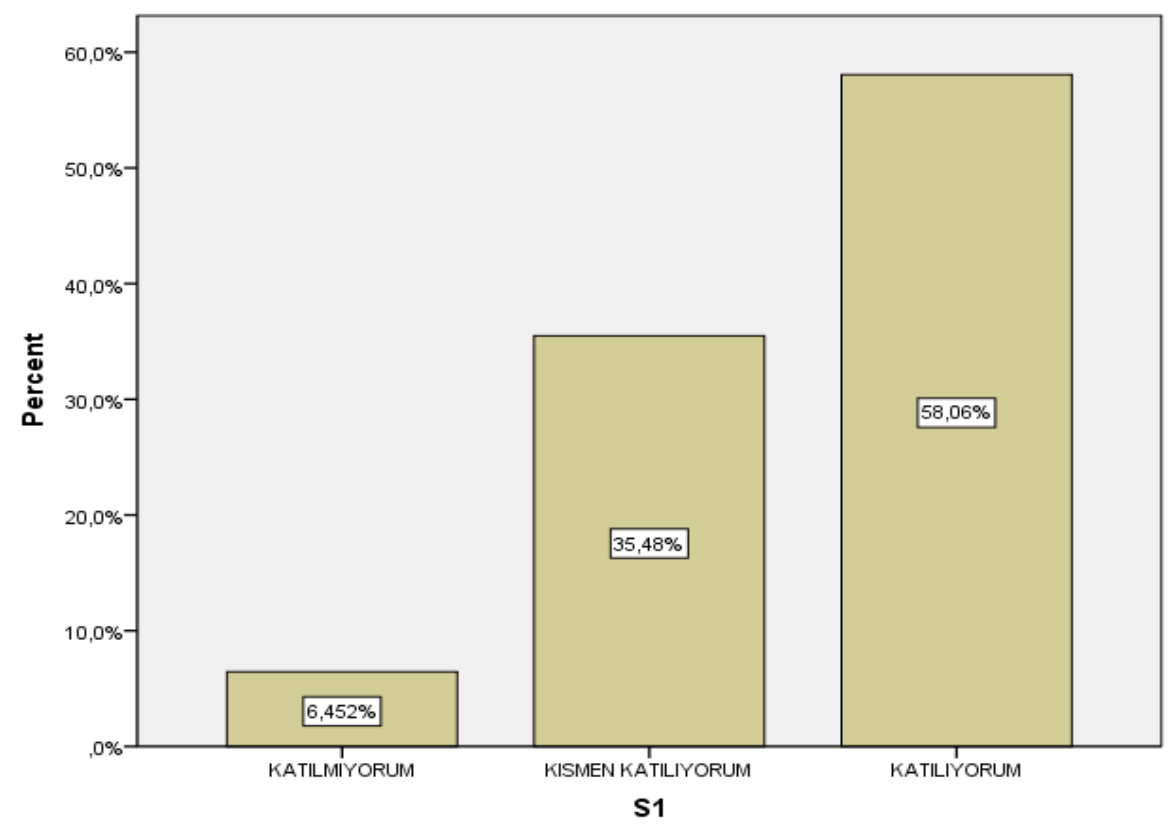


Table 3. Question 10 What I Have Learned In This Session Makes Sense

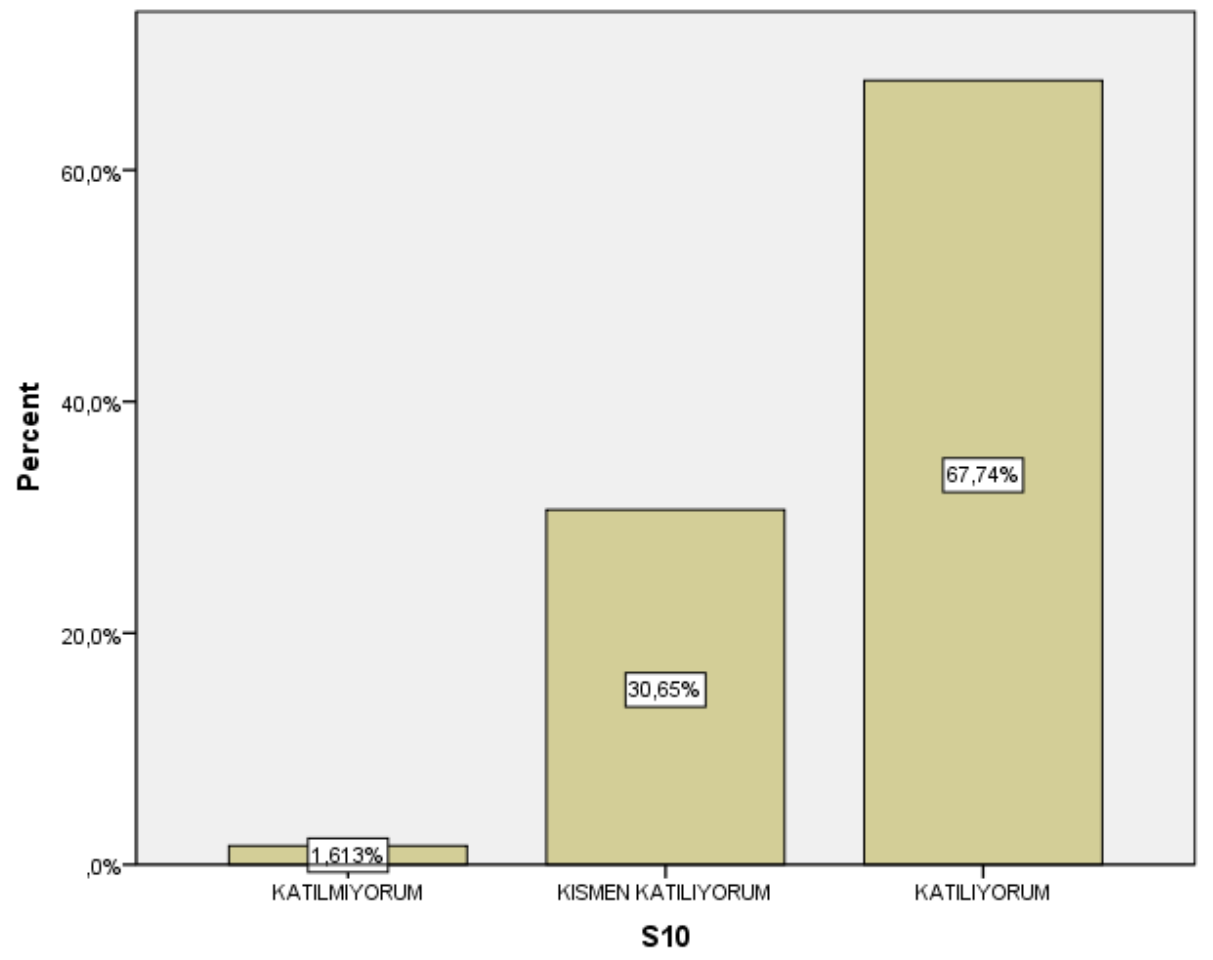

Table 4. Question 12: I Have Understood the Main Concepts

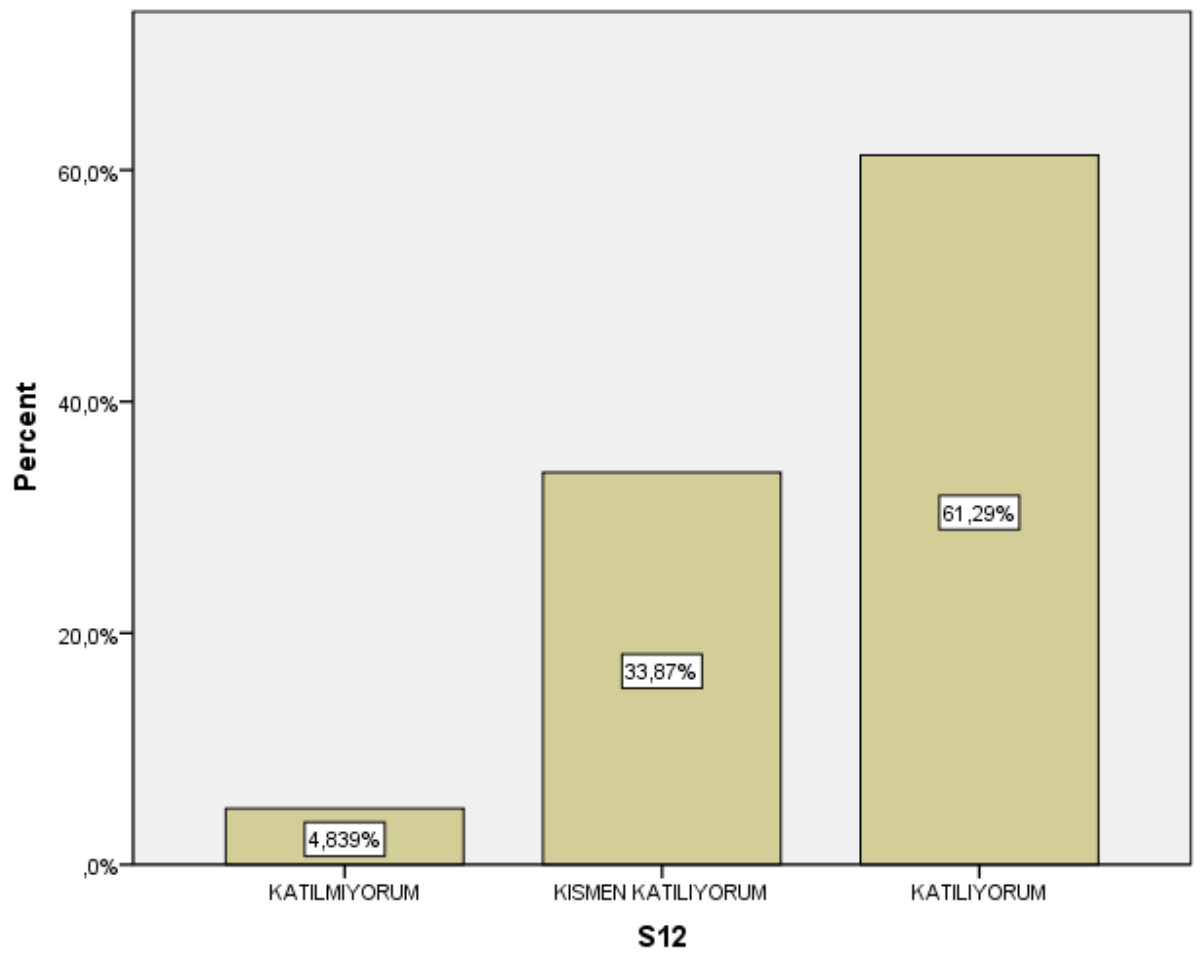




\section{Teamwork}

On Question 9 (Table 5), 69.35\% of students expressed that the teamwork that took place in this session had a positive effect on their learning. They also mentioned that they enjoyed working on the real-world scenarios as a team, which boosted their confidence; this was cited as one of the things they enjoyed the most in the application of TBL. In the focus group, they agreed that working in a team aided in developing their teamwork skills. They also expressed that providing a setting where they had a chance to discuss the tRAT within their teams encouraged them to contribute more.

The focus group also mentioned that teamwork provided them an opportunity to see their weaknesses around the topic.

Table 5. Question 9 the Teamwork That Took Place in This Session Had A Positive Effect on my Learning

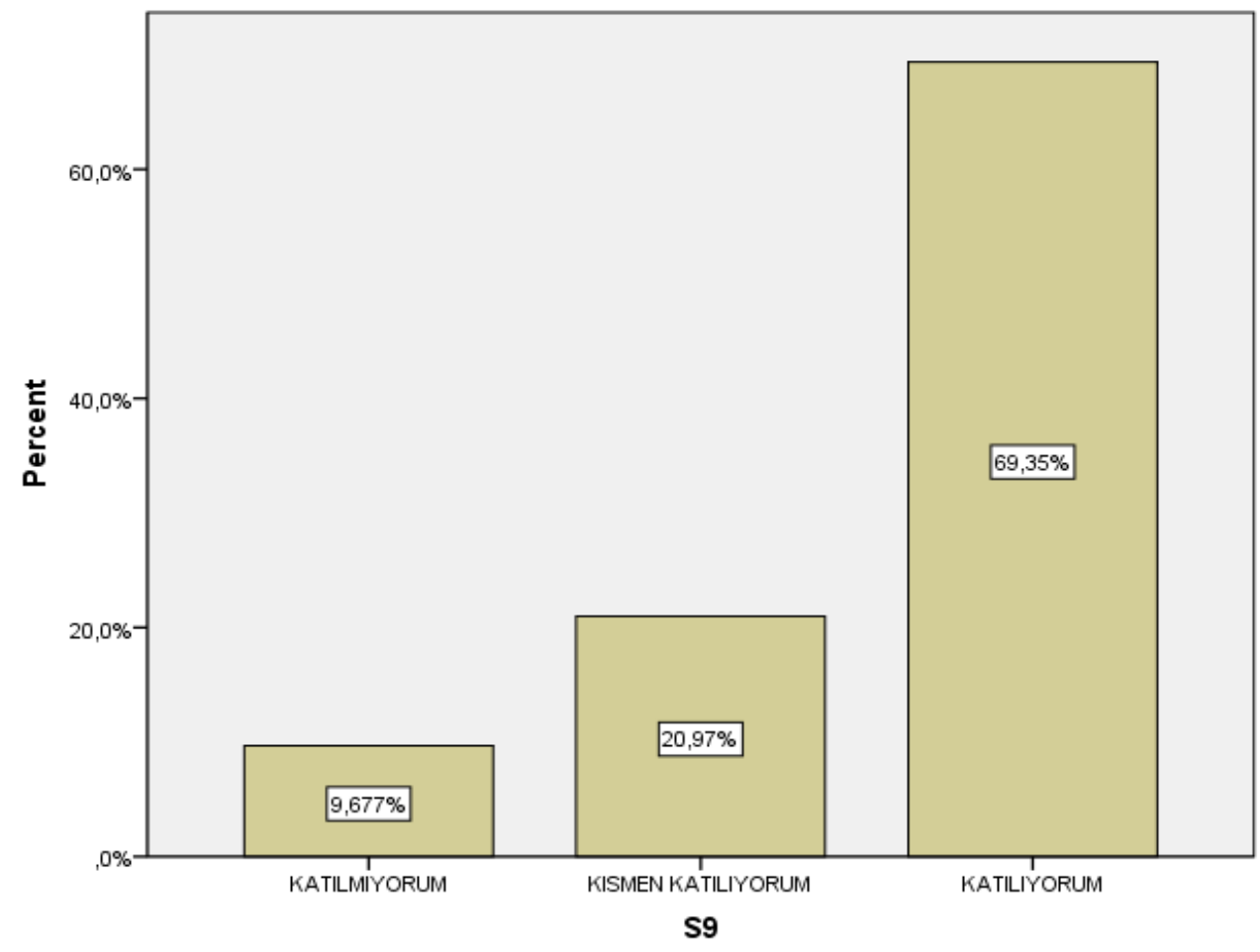

\section{Scratch-able Cards}

In TBL, each team receives one scratch-able answer sheet in their folder in order to use it during the tRAT. After they decide on the answer as a team, they scratch off the covering of one of four boxes in search of a mark / star which indicates that they have found the correct answer.

Students expressed that scratch-able cards was another element that they greatly enjoyed in the application of TBL, since these added excitement to the process. It also forced them to discuss the results, since none of the team members wanted to scratch the wrong choice. 


\section{Reporting/Evaluation}

Students said that they found the reporting part at the end useful. Reporting provided them an opportunity to hear different perspectives and solutions for the case study.

\section{Classroom Decorum}

When asked what they would like to change, nearly all of the students answered, "classroom." Later in the focus group, when the same question was asked, students responded that the classroom where the course took place should be changed, as it is not suitable for teamwork and learning. They said, "it is dark, tight and stuffy."

Disrespectful students came out as a second element by which some students were bothered. Several pointed out that students should respect each other, be quiet and listen when other groups are reporting. When this issue was mentioned to the instructor, her explanation was:

"... Students are already tired. They would like to be done (with this course) and go to their home as soon as possible. They have lost their focus ... I am even amazed that they managed to stay in the class until the end (of this session).... usually they leave early ..."

Table 6. Question 11 the Preparation That I Have Done Before This Session Helped Me to Follow the Session

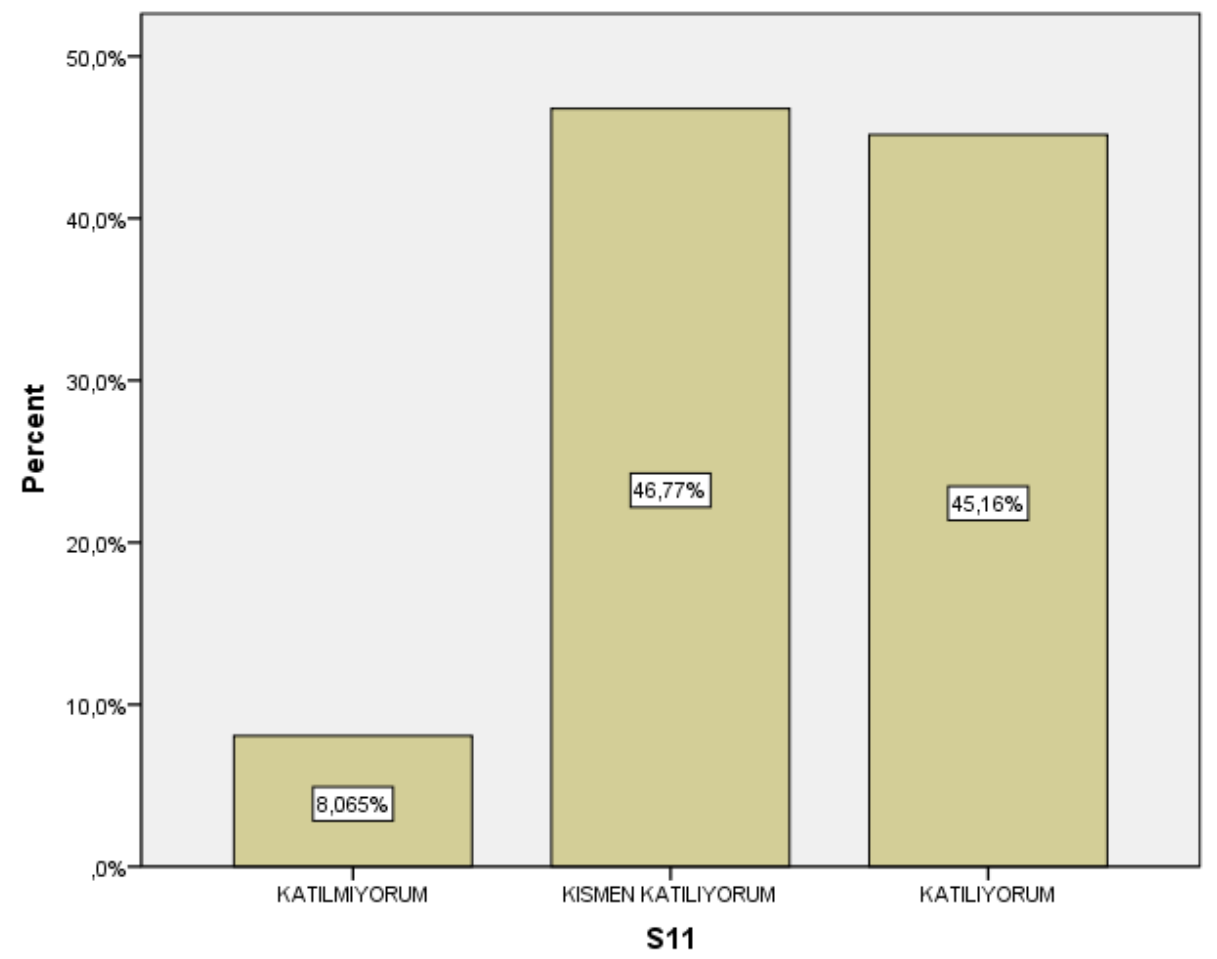




\section{Discussion}

The study results indicate that students evaluate the team-based learning (TBL) model positively. As it was mentioned by students, they would like to see more of their lecturers apply TBL in their courses.

Accountability was an issue of concern, as less than half of the students said that they came to the first session without reading the material. During the second session, students reported having read the material before coming to the session. Reading the materials beforehand is a crucial step for the TBL method to run smoothly. As $45.16 \%$ students responded on Question 11 (Table 6), their preparation before this session helped them to follow the session. This shows that a pre-TBL training session is not just crucial for the instructor but also for the students. During such a session, the instructor would have to explain why students are accountable for coming to class prepared and that "accountability is the cornerstone of team-base learning" (Sutherland et al. 2013).

Reporting is one of the phases of TBL in which students' knowledge is put to the test. As Zeng, Xiang, Zeng, and Zuo (2017) and others have mentioned (Terenzini et al. 2001; Haidet et al., 2012; Prince, 2004; Nieder, Parmelee, Stolfi, \& Hudes, 2005; Koles, Stolfi, Borges, Nelson, \& Parmelee, 2010; Emke, Butler, \& Larsen, 2016), reporting also provides students with an environment in which they are required to apply their knowledge in order to solve real-world scenarios within a cooperative learning environment. In this study, students expressed that teamwork boosted their self-confidence, stimulated an interest in learning, and improved their ability to solve problems. Since teamwork is crucial for TBL to work effectively, it would be useful to incorporate a workshop on this valuable skill before the session, since students in Turkey lack experience in that area.

Michaelsen, Sweet, \& Parmalee (2009) have suggested that teams present their case studies sequentially or simultaneously. We found in our study that simultaneous reporting works better for the teams. That way teams do not attempt to copy from each other.

\section{Limitations}

As mentioned above, most of the steps of team-based learning (TBL) were implemented, except for the written appeals and peer evaluations. This was decided partly because of the lack of preparedness of the students, as well as due to time concerns. In addition, students in this cultural context are not familiar with evaluating each other's performance (Frisby, Slone, \& Bengu, 2017) and they see no point doing that. As Thompson et al. (2007) have also mentioned, students do not see this as "a professional development experience" and they tend to give the same grade to their peers. Therefore, in this study we couldn't evaluate the effects of peer evaluation. 


\section{Conclusions}

A growing body of research indicates that the team-based learning (TBL) model, which is an example of an active and collaborative approach to teaching, is an effective instructional model. In this study, we have also looked at its effectiveness in night classes, which are characterized by fatigued, less motivated students. The results showed that TBL energized students and triggered their motivation in learning more about the topic.

The study showed that TBL in a Turkish university setting can be an educational tool that encourages teamwork and makes an active learning session more interactive, engaging and fun. Furthermore, for TBL to be successful, students should be made accountable of their own learning, but at the same time, it is imperative that the teacher also properly plans the pre-readings, case scenarios and activities (Sutherland, Bahramifarid, \& Jalali, 2013). Although it would seem the instructor takes on a passive role in the classroom, she has to provide timely and active feedback to students (Michaelsen et al. 2008; Sutherland, Bahramifarid, \& Jalali, 2013).

It is suggested, therefore, that despite the high power distance characterizing the Turkish culture, Turkish university institutions and departments would benefit from providing professional development workshops for instructors who are interested in using TBL in their classrooms. The use of this method would not only make their students' learning more profound, but would also benefit the teachers themselves, for it leads to more motivated and engaged class participants.

\section{Final Thoughts}

The results showed that team-based learning (TBL) is an active learning method that is learner-centered and instructor-guided. A possible next step for this researcher will be to apply TBL to other subject fields, such as engineering and architecture courses, within the technical university where she is employed. In addition to that, she would like to provide a workshop for instructors about the use of team-based learning and work with those who are interested in applying this method in their own courses.

\section{Acknowledgements}

I would like to express my sincere thanks to Raife Badak Aşık for letting me apply the method in her classroom; Soultana Kalligas for proofreading this paper; and Cengiz Gazeloğlu for his assistance in analyzing the data. 


\section{References}

Bidabadi, S.N., Isfahani, N. A., Rouhollahi, A., \& Khalili, R. (2016). Effective Teaching Methods in Higher Education: Requirements and Barriers. Journal of Advances in Medical Education \& Professionalism, 4(4), 170-178.

Chung, E.K., Rhee, J.A., Baik, Y.H., \& Oh-Sun, A. (2009). The Effect of Team-based Learning in Medical Ethics Education. Medical Teacher, 31, 1013-1017. DOI= 10.3109/01421590802590553.

Dolmans, D., Michaelsen, L., Van Merrienboer, J., \& Van der Vleuten, C. 2015. Should we choose between Problem-based Learning and Team-based Learning? No, combine the best of both worlds!. Medical Teacher, 37, 354-359.

Emke, A. R., Butler, A. C., \& Larsen, D. P. (2016). Effects of Team-Based Learning on Short-term and Long-term Retention of Factual Knowledge. Medical Teacher, 38(3), 306-311.

Fatmi, M., Hartling L., Hillier T., Campbell S., \& Oswald, A.E. (2013). The Effectiveness of Team-based Learning on Learning Outcomes in Health Professions Education: BEME Guide No. 30. Medical Teacher, 35, 1608-1624.

Fraenkel, J., Wallen, N., \& Hyun, H. (2011). How to Design and Evaluate Research in Education, 8th ed. New York: McGraw-Hill.

Frisby, B. N., Slone, A. R., \& Bengu, E. (2017). Rapport, Motivation, Participation, and Perceptions of Learning in U.S. and Turkish Student Classrooms: A Replication and Cultural Comparison. Communication Education, 66(2), 183-195.

Haidet, P., Levine, R.E., Parmelee, D.X., Crow, S., Kennedy, F., Kelly, A., Perkowski, L., Michaelsen, L., \& Richards, B.F. (2012). Guidelines for Reporting Team-based Learning Activities in the Medical and Health Sciences Education Literature. Academic Medicine, 87(3), 292-299.

Hrynchak, P., \& Batty, H. (2012). The Educational Theory Basis of Team-based Learning. Medical Teacher, 34, 796-801.

Koles, P.G., Stolfi, A., Borges, N.J., Nelson, S., \& Parmelee, D.X. (2010). The Impact of Team-based Learning on Medical Students' Academic Performance. Academic Medicine, 85, 1739-1745.

McInerney, M., \& Fink, L.D. (2003). Team-based Learning Enhances Long-term Retention and Critical Thinking in an Undergraduate Microbial Physiology Course. Journal of Microbiology \& Biology Education, 4, 1-18.

Michaelsen, L. K., Parmelee, D. X., McMahon, K. K., \& Levine, R.E. (Eds.) (2008). Teambased Learning for Health Professions Education: A Guide to using Small Groups for Improving Learning. Sterling, VA: Stylus Publishing.

Michaelsen, L., Sweet, M., \& Parmalee, D. (2009). Team-Based Learning: Small Group Learning's Next Big Step. New Directions in Teaching and Learning, 7-27.

Nieder, G.L., Parmelee, D.X, Stolfi, A., \& Hudes, P.D. (2005). Team-based Learning in a Medical Gross Anatomy and Embryology Course. Clinical Anatomy, 18, 5663.

Parmalee, D. Michaelsen, LK, Cook, S., \& Hudes, P.D. (2012). Team-based Learning: A Practical Guide: AMEE guide no. 65, 34(5), 275-287.

Prince, M. (2004). Does active Learning Work? A Review of the Research. Journal of Engineering Education, 93, 223-231.

Salam, A., Bujang, S.M., Kamarudin, M.A., Yaman, MN, Siraj, H. H., \& Mohamad, N. (2016). Preparedness of the Teachers for Team Based Learning: Liking, Disliking, and Suggestions of Faculty. Journal of Applied Pharmaceutical Science, 6(03), 077080 . 
Searle, N.S., Haidet, P., Kelly, P.A., Schneider, V.F., Seidel, C.L., \& Richards, B.F. (2003). Team Learning in Medical Education: Initial Experiences at Ten Institutions. Academic Medicine, 78, S55-S58.

Shellenberger, S., Seale, J.P., Harris, D.L., Johnson, J.A., Dodrill, C.L., \& Velasquez, M.M. (2009). Applying Team-based Learning in Primary Care Residency Programs to Increase Patient Alcohol Screenings and Brief Interventions. Academic Medicine, 84, 340-346.

Sutherland, S., Bahramifarid, N., \& Jalali, A. (2013). Team-based Learning from Theory to Practice: Faculty Reactions to the Innovation. Teaching and Learning in Medicine, 23(3), 231-236.

Tatar, S., (2005). Classroom Participation by International Students: The Case of Turkish Graduate Students. Journal of Studies in International Education, 9, 337-355.

Terenzini, P.T., Cabrera, A.F., Colbeck, C.L., Parente, J.M., \& Bjorklund, S.A. (2001) Collaborative Learning versus lecture/discussion: Students' Reported Learning Gains. Journal of Engineering Education, 90,123-130.

Thompson, B.M., Schneider, V.F., Haidet, P., Levine, R.E, McMahon, K.K, Perkowski, L.C., \& Richards, B.F. (2007). Team-based Learning at Ten Medical Schools: Two Years Later. Medical Education, 41, 250-257.

Topbas, E. (2013). A Comparison of Teacher Training Programs in Turkey and Finland. International Journal of Academic Research Part B, 5, 111-120.

Wiener, H., Plass, H., \& Marz, R. (2009). Team-based Learning in Intensive Course Format for First-year Medical Students. Croatian Medical Journal, 50, 69-76.

Yildirim, I. (2006). Daily Hassles and Social Support as Predictors of Academic Achievement. Hacettepe University Journal of Education, 30, 258-267.

Zeng, R., Xiang, L., Zeng, J., \& Zuo, C. (2017). Applying Team-based Learning of Diagnostics for Undergraduate Students: Assessing Teaching Effectiveness by a Randomized Controlled Trial Study. Advances in Medical Education and Practice, 8 , 211-218. 
